\title{
Meta-analysis of Vascular Imaging Features to Predict Outcome Following Intravenous rtPA for Acute Ischemic Stroke
}

\author{
Ricardo C. Nogueira ${ }^{1 *}$, Edson Bor-Seng-Shu ${ }^{2}$, Nazia P. Saeed ${ }^{3}$, Manoel J. Teixeira ${ }^{2}$, \\ Ronney B. Panerai ${ }^{3,4}$ and Thompson G. Robinson ${ }^{3,4}$ \\ 'Department of Neurology, Hospital das Clínicas, University of São Paulo School of Medicine, São Paulo, Brazil, \\ ${ }^{2}$ Department of Neurosurgery, Hospital das Clínicas, University of São Paulo School of Medicine, São Paulo, Brazil, \\ ${ }^{3}$ Department of Cardiovascular Sciences, University of Leicester, Leicester, England, ${ }^{4}$ Biomedical Research Unit in \\ Cardiovascular Science, Glenfield Hospital, Leicester, England
}

Background: The present review investigated which findings in vascular imaging techniques can be used to predict clinical outcome and the risk of symptomatic intracerebral hemorrhage $(\mathrm{s} \mathrm{CH})$ in patients who underwent intravenous thrombolytic treatment.

Methods: Publications were searched, and the inclusion criteria were as follows: (1) published manuscripts, (2) patients with acute ischemic stroke managed with intravenous recombinant tissue plasminogen activator (rtPA), and (3) availability of imaging assessment to determine vessel patency or the regulation of cerebral blood flow prior to, during, and/or after thrombolytic treatment. Clinical outcomes were divided into neurological outcome [National Institutes of Health Stroke Scale (NIHSS) within 7 days] and functional outcome (modified Rankin score in 2-3 months). sICH was defined as rtPA-related intracerebral bleeding associated with any worsening of NIHSS.

Results: Thirty-nine articles were selected. Recanalization was associated with improved neurological and functional outcomes $(\mathrm{OR}=7.83 ; 95 \% \mathrm{Cl}$, 3.71-16.53; $p<0.001$ and $\mathrm{OR}=11.12 ; 95 \% \mathrm{Cl}, 5.85-21.14 ; p<0.001$, respectively). Both tandem internal carotid artery/middle cerebral artery (ICA/MCA) occlusions and isolated ICA occlusion had worse functional outcome than isolated MCA occlusion $(\mathrm{OR}=0.26,95 \% \mathrm{Cl}, 0.12-0.52$; $p<0.001$ and $\mathrm{OR}=0.24,95 \% \mathrm{Cl}, 0.07-0.77 ; p=0.016$, respectively). Reocclusion was associated with neurological deterioration $(\mathrm{OR}=6.48,95 \% \mathrm{Cl}, 3.64-11.56 ; p<0.001)$, and early recanalization was associated with lower odds of $\mathrm{sICH}(\mathrm{OR}=0.36,95 \% \mathrm{Cl}$, $0.18-0.70 ; p=0.003)$.

Conclusion: Brain circulation data before, during, and after thrombolysis may be useful for predicting the clinical outcome. Cerebral arterial recanalization, presence and site of occlusion, and reocclusion are all important in predicting the clinical outcome.

Keywords: ischemic stroke, clinical outcome, intracerebral hemorrhage, cerebral hemodynamics, intracranial circulation, cerebral autoregulation, rtPA 


\section{INTRODUCTION}

A meta-analysis of recombinant tissue plasminogen activator (rtPA) trials suggested that there may be a group of patients who would benefit from thrombolysis within $6 \mathrm{~h}$ of symptom onset, if they were carefully selected using advanced imaging modalities (1).

There has been an extensive investigation of prognostic indices of good outcomes that can be applied before, during, and after thrombolysis (2). It is well known that factors, such as age, initial National Institutes of Health Stroke Scale (NIHSS) score, and systolic blood pressure, are of predictive value for clinical outcome and symptomatic intracerebral hemorrhage (sICH) (3). Magnetic resonance imaging (MRI), computed tomography (CT), and transcranial Doppler (TCD) have also been used as possible prognostic determinant tools (4). In particular, arterial occlusion, recanalization, and reocclusion, among other factors, have been investigated in terms of outcome prediction (4). However, there is a gap in the literature about how many methods, which evaluate intracranial circulation, have been used before and after thrombolysis to predict the outcome in a systematic fashion, together with a critical review of the strengths and weaknesses of each method.

The aim of the present review is (1) to undertake a descriptive systematic review of studies that have evaluated the intracranial circulation before, during, and after thrombolysis; (2) to evaluate the parameters that provide prognostic information of clinical outcome and/or sICH; and (3) to perform a meta-analysis of studies that used such parameters.

\section{MATERIALS AND METHODS}

\section{Search Strategy}

A literature search strategy, restricted to publications from January 1994 to January 2015, was designed to identify cerebral hemodynamic studies, which assessed cerebral vessel patency and/or autoregulation in acute ischemic stroke patients treated with intravenous rtPA. Two reviewers (Ricardo C. Nogueira and Nazia P. Saeed) identified studies from PubMed database using the keywords "ischemic stroke" AND "rtPA treatment" OR "thrombolysis" AND "cerebral hemodynamics" OR "cerebral autoregulation" OR "cerebral blood flow control." Bibliographic references of selected articles were examined for additional suitable studies. The inclusion criteria were (1) published manuscripts in English language, (2) patients ( $>18$ years of age) with acute ischemic stroke treated with intravenous rtPA, and (3) availability of assessment of intracranial circulation to determine vessel patency and/or regulation of cerebral blood flow prior to, during, and/or after thrombolytic treatment. The exclusion criteria were (1) acute ischemic stroke not managed with intravenous rtPA, (2) impossibility to determine the vessel patency or the regulation of cerebral blood flow before, during, and/or after rtPA administration, (3) non-English language publications, (4) non-human models, and (5) case reports. The systematic review followed PRISMA guidelines; quality assessment of articles were used applying the American Academy of Neurology rating system by two raters (Ricardo C. Nogueira and Nazia P. Saeed), reviewed by a third investigator (Edson Bor-Seng-Shu) in terms of agreement, and this individual resolved any discrepancies. For the meta-analysis, authors of publications with incomplete data were contacted for additional information. Moreover, care was taken to exclude articles with no comparable data (for example: lack of imaging after thrombolysis, lack of clinical outcome measured, etc.) and articles with patients included in other articles from the same institution to avoid biasing the population sample.

\section{Data Extraction}

The following data were extracted from each article: sample size, presence of a control group, type(s) of diagnostic modality used, time delay between assessment and thrombolysis (when stated), time interval between rtPA treatment and monitoring examinations (assessment during and following treatment, when stated), outcomes, conclusions, and study limitations. The articles were grouped according to the method of cerebral hemodynamic assessment. Data from cerebral hemodynamic assessment techniques were compared based on their common aspects, primary contributions, and limitations.

\section{Outcomes}

Clinical outcomes were divided into functional, defined by modified Rankin scale (mRS) in the late post-thrombolytic therapy (2-3 months) with good outcome been considered as mRS $\leq 2$, and neurological outcomes, assessed by NIHSS and comprising improvement (reduction of 10 points or final NIHSS $\leq 3$ ) or deterioration (increase $\geq 4$ points) in the early post-thrombolytic therapy stage (within 7 days). sICH was defined as rtPA-related intracerebral bleeding detected by CT or MRI associated with any worsening of NIHSS or death. Additional outcome measures were arterial recanalization assessed by different scales [thombolysis in brain ischemia (TIBI), thrombolysis in myocardial ischemia (TIMI), and partial or full recanalization], reocclusion (within $24 \mathrm{~h}$ ), and cerebral infarct volume.

\section{Meta-analysis}

The variables related to assessment of intracranial circulation were identified in each retrieved paper and, if they presented in the results a significant correlation with clinical outcome and $\mathrm{sICH}$ in a multivariate analysis, they were considered for the meta-analysis. The software used for meta-analysis was the OpenMetaAnalyst (Center for Evidence-based Medicine, Brown University School of Public Health - Providence, RI, USA), the binary random-effect method was applied, and the heterogeneity of studies was evaluated using $I^{2}$ statistics. To identify for publication bias, a funnel plot and Egger's test were applied in the analysis of any assessed variable, where information was available from three or more studies.

\section{RESULTS}

\section{Number of Studies Retrieved}

The search in PubMed retrieved 7369 articles. After analyzing the title and abstract, a total of 278 articles were deemed suitable. The inclusion and exclusion criteria were then applied, leaving 39 articles for further analysis (Figure 1). Each article was then grouped 
according to the neuroimaging technique performed; 26 studies used TCD ultrasonography, 2 computed tomography angiography (CTA), 10 magnetic resonance imaging angiography (MRA), and 1 either MRA or CTA. TCD ultrasonography was the most used method for cerebral hemodynamic evaluation and was, on average, performed on more patients per study, besides presenting the shortest time interval for follow-up assessment (average $2.4 \mathrm{~h}$ ).

\section{Characteristics of the Included Studies}

There were 38 observational studies ( 37 cohort and 1 case-control) and 1 interventional study; no randomized controlled clinical trial was identified (please see Supplementary Material). The majority of the observational studies (36 of 38) used the neuroimaging methods for prognostic purposes, and the remainder used the methods for investigating diagnostic accuracy or causation.

After grouping the articles based on the type of cerebral hemodynamic assessment, common findings were as follows.

\section{MR/CT Angiography}

Thirteen studies using CTA (2 studies), MRA (10 studies), or MRA + CTA (1 study) were included (please see Supplementary Material) (5-17). In two studies (one using MRA and another CTA), neuroimaging assessment was not performed after rtPA treatment. The mean time delay from neuroimaging examination to thrombolytic therapy was $40 \mathrm{~min}$, and the mean time for a second exam following therapy was $19.2 \mathrm{~h}$. One study had an interventional design, and the main outcomes were functional and recanalization (TIMI 1-3). rtPA was associated with higher rates of recanalization and better functional outcomes. Concerning the observational studies, the findings revealed that the presence, site of arterial occlusion [proximal middle cerebral artery (MCA), distal MCA, or tandem internal carotid artery (ICA)-MCA], and the occurrence of partial or full recanalization were related to the clinical outcomes and final infarct size. The limitations included

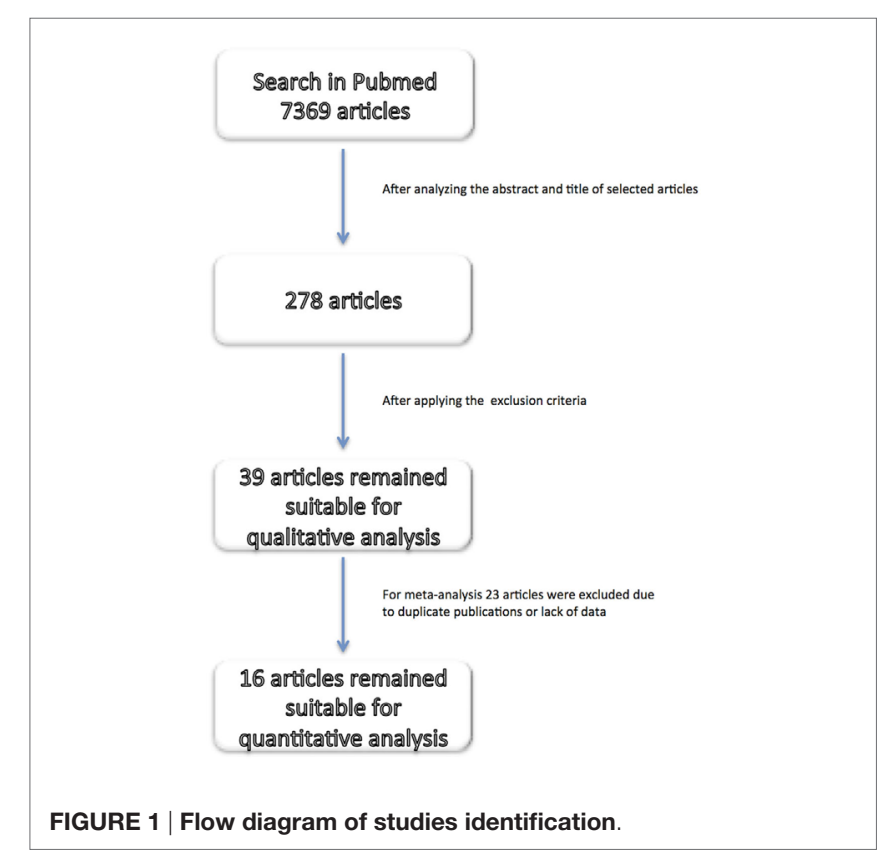

a small sample size and difficulties in determining the time of arterial recanalization.

\section{Transcranial Doppler}

Twenty-six studies used TCD as a method for cerebral hemodynamic assessment (please see Supplementary Material) (3, 18-42). In 24 studies, cerebral hemodynamic parameters were evaluated prior to and after thrombolytic treatment (range from $2 \mathrm{~h}$ to 2 days), while the remaining 2 studies presented only pre-rtPA cerebral hemodynamic data. TCD was the sole method for monitoring the cerebral hemodynamic status during thrombolysis.

These studies revealed that factors, such as pretreatment TIBI classification score, arterial recanalization/reocclusion, and the site of occlusion (tandem occlusions, proximal/distal ICA, or MCA occlusions), were associated with clinical outcome, infarct size, and sICH.

Limitations included the operator-dependence nature of the TCD method, the absence of arterial imaging resources (making it difficult to determine the site of occlusion), and unfavorable cranial windows for ultrasound energy passage.

\section{Pooled Results}

The cerebral circulation variables associated with functional and neurological outcomes or sICH were arterial recanalization/ reocclusion, presence/absence of arterial occlusion, and the site of occlusion (Tables 1 and 2). No article regarding cerebral autoregulation (CA) was identified.

For the meta-analysis, 23 out of 39 articles were excluded for the following reasons: possibility of overlapping patients (12 articles, 964 patients), lack of data able to be compared (6 articles, 360 patients), and lack of success in obtaining additional data (5 articles, 129 patients). Arterial recanalization was significantly associated with good functional outcome $(\mathrm{OR}=11.12$; 95\% CI, 5.85-21.14; $p<0.001)$ and neurological improvement (OR $=7.83$; 95\% CI, 3.71-16.53; $p<0.001)$ (Figures 2A,B). Both tandem ICA/MCA occlusions and isolated ICA occlusion had worse functional outcome than isolated MCA occlusion $(\mathrm{OR}=0.26,95 \% \mathrm{CI}, 0.12-0.52 ; p<0.001$ and $\mathrm{OR}=0.24$, 95\% CI, 0.07-0.77; $p=0.016$, respectively) (Figures 2C1,C2). Patients with recanalization followed by reocclusion within $24 \mathrm{~h}$ of thrombolysis had significant association with neurological deterioration (overall OR: 6.48, 95\% CI: 3.64-11.56, $p<0.001$ ) (Figure 2D). Early recanalization (up to $2 \mathrm{~h}$ after thrombolysis) was associated with lower odds of sICH (overall OR $=0.36,95 \%$ CI, 0.18-0.70; $p=0.003$ ) (Figure 3).

The funnel plots of functional outcomes and sICH were suggestive of potential publication bias, which was confirmed by the Egger's test (intercept: $43.65, p=0.046$; intercept: $1.97, p=0.003$; Figures 4A,B, respectively). However, the funnel plot of neurological improvement did not indicate the publication bias (Egger's test intercept: $1.48, p=0.83$; Figure $4 \mathrm{C}$ ).

\section{DISCUSSION}

In 2003, Schellinger et al. (43) highlighted the importance of various diagnostic modalities, such as brain MRI, CT, and TCD 
TABLE 1 | Studies demonstrating association with clinical outcome.

\begin{tabular}{|c|c|c|c|c|}
\hline Article & Method & Variable & Outcome & Result \\
\hline Molina et al. (19) & TCD & Early recanalization (6 h) & Good outcome (mRS $\leq 2)$ in 90 days & $\mathrm{OR}=23.4(5.4-96) p=0.001$ \\
\hline $\begin{array}{l}\text { Nighoghossian et al. } \\
\text { (12) }\end{array}$ & $\begin{array}{l}\text { Multiparametric } \\
\text { MRI }\end{array}$ & Recanalization & NIHSS at day 60 & $\begin{array}{l}\text { Multiple linear regression } \\
p=0.0001\end{array}$ \\
\hline Molina et al. (3) & TCD & Proximal occlusion before thrombolysis & Good outcome (mRS $\leq 2)$ in 90 days & $\mathrm{OR}=0.25(0.10-0.61) p<0.001$ \\
\hline Sims et al. (17) & CTA & Absence of occlusion & Early improvement (4 points in NIHSS) & $\mathrm{OR}=5.0(1.1-23.3) p=0.04$ \\
\hline Sims et al. (17) & CTA & Absence of occlusion & Good outcome (mRS $\leq 2)$ in 7 days & $\mathrm{OR}=6.8(1.3-34.6) p=0.02$ \\
\hline Saqqur et al. (42) & TCD & Reocclusion & Clinical deterioration (4 points in NIHSS) & $\mathrm{OR}=4.9(1.7-13) p=0.002$ \\
\hline Saqqur et al. (41) & TCD & $\begin{array}{l}\text { Distal } \times \text { proximal MCA occlusion before } \\
\text { thrombolysis }\end{array}$ & Good outcome (mRS $\leq 1)$ in 90 days & $\mathrm{OR}=2.1(1.1-4) p=0.025$ \\
\hline Tsivgoulis et al. (34) & TCD & Recanalization within $2 \mathrm{~h}$ & Good outcome (mRS $\leq 2)$ in 90 days & $\mathrm{OR}=5.98(2.58-13.84) p<0.001$ \\
\hline
\end{tabular}

TABLE 2 | Studies demonstrating association with symptomatic intracerebral hemorrhage.

\begin{tabular}{|c|c|c|c|c|}
\hline Article & Method & Variable & Outcome & Result \\
\hline Saqqur et al. (36) & TCD & Persistence of occlusion $\geq 2 \mathrm{~h}$ & $\mathrm{sICH}$ & $\mathrm{OR}=6(1.5-21.3) p=0.01$ \\
\hline Saqqur et al. (36) & TCD & Recanalization beyond $24 \mathrm{~h}$ or persistent occlusion & $\mathrm{SICH}$ & $\mathrm{OR}=3(1.1-10) p=0.04$ \\
\hline Saqqur et al. (36) & TCD & Persistence of proximal occlusion at $2 \mathrm{~h}$ & $\mathrm{slCH}$ & $\mathrm{OR}=5(1.5-15) p=0.008$ \\
\hline Saqqur et al. (36) & TCD & Persistence of proximal occlusion at $2 \mathrm{~h}$ (excluding reocclusion) & $\mathrm{SICH}$ & $\mathrm{OR}=8(3-26) p<0.001$ \\
\hline
\end{tabular}

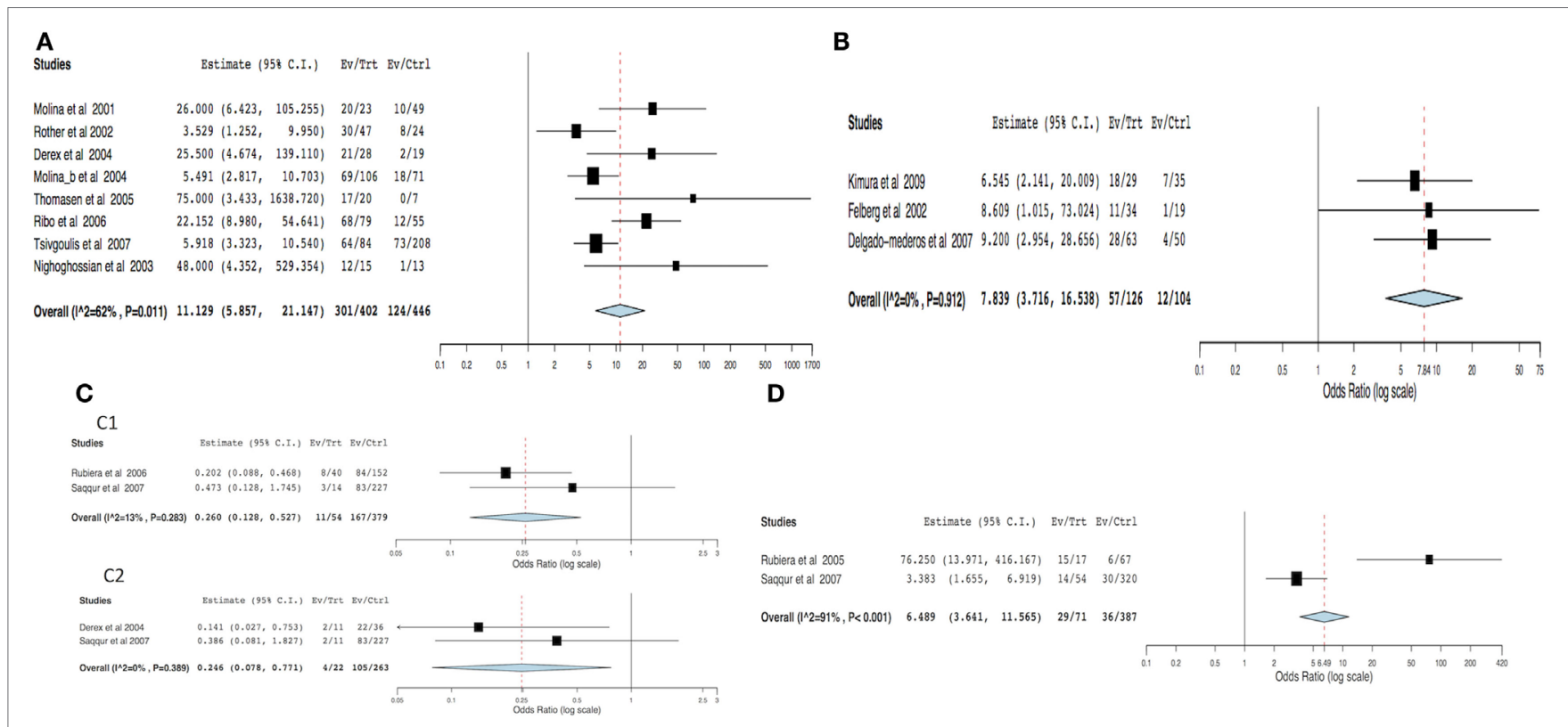

FIGURE 2 | Meta-analysis of hemodynamic variables related to clinical outcome. (A) Functional outcome (dichotomized mRS) in recanalized versus non-recanalized patients. (B) Neurological outcome (NIHSS) in recanalized versus non-recanalized patients. (C) Functional outcome (dichotomized mRS) by site of occlusion: (C1) tandem ICA-MCA versus isolated MCA and (C2) isolated ICA versus isolated MCA. (D) Clinical deterioration in recanalization versus reocclusion patients. MCA - middle cerebral artery, ICA - internal carotid artery, NIHSS - National Institute of Health Stroke Scale, and mRS - modified Rankin scale.

ultrasonography, for the decision-making process regarding thrombolytic therapy for acute ischemic stroke. Furthermore, the assessment of cerebral hemodynamic during and after thrombolytic therapy may be important to determine the parameters that could influence the clinical outcome, especially in the face of new research investigating the aggressive control of ABP in this scenario (44). Finally, with the new guidelines regarding endovascular treatment (45), the evaluation of cerebral circulation will be useful to determine proximal occlusion and also could select patients who were excluded from endovascular trials, but could benefit from the interventional therapy. To our knowledge, the present paper is the first to use techniques of systematic review and meta-analysis to verify the influence of assessment of intracranial circulation, provided by brain MRI, 


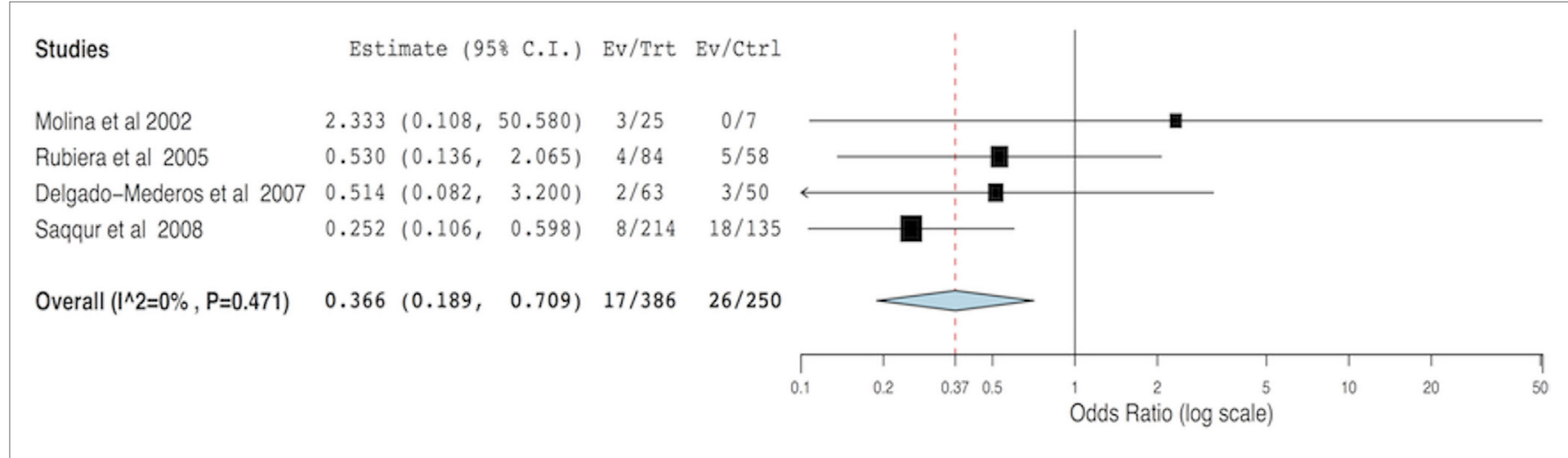

FIGURE 3 | Meta-analysis of the hemodynamic variables recanalization versus non-recanalization related to symptomatic intracerebral hemorrhage.

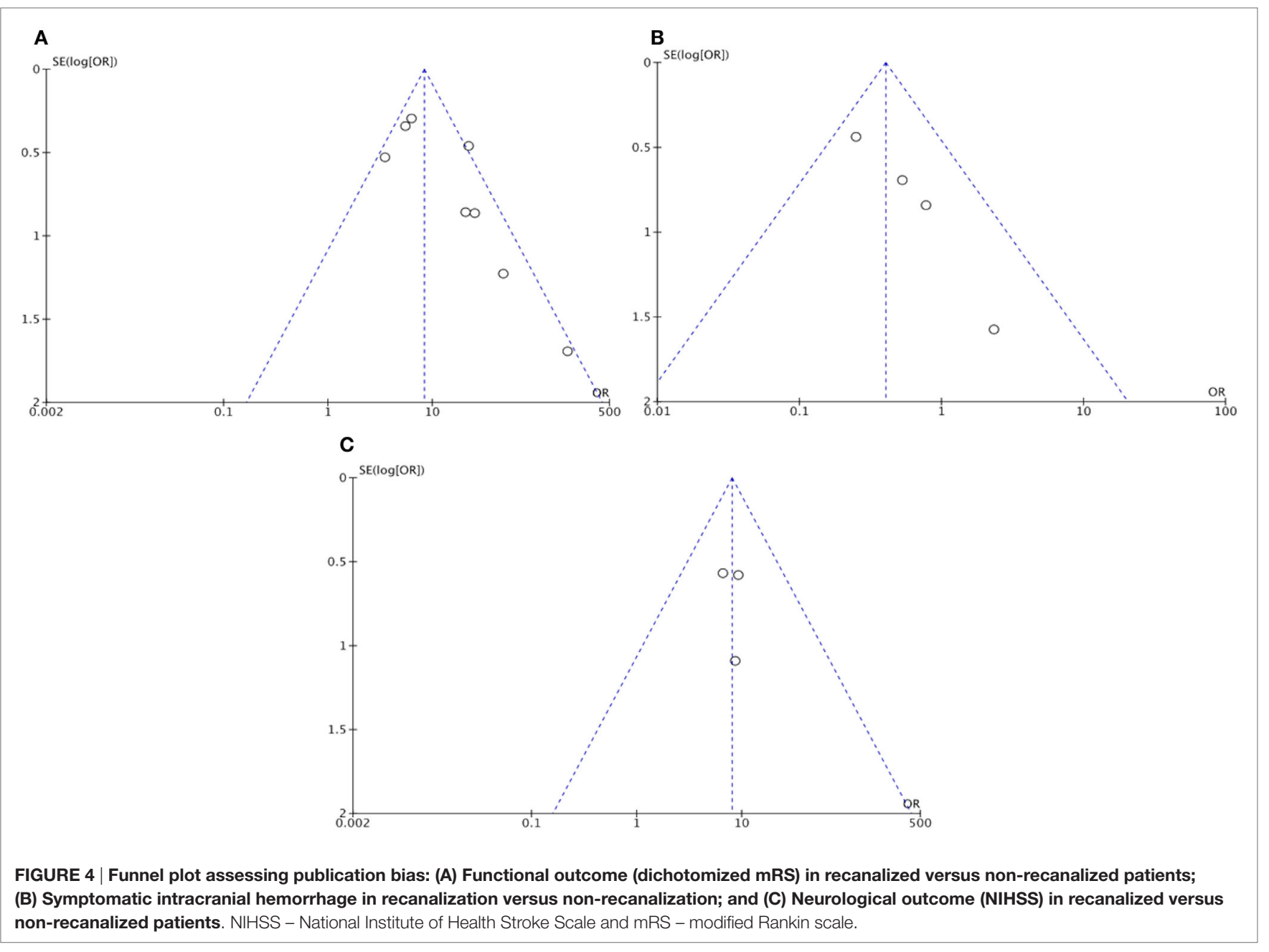

CT, and TCD ultrasonography on clinical outcomes and sICH in acute ischemic stroke patients who underwent thrombolytic therapy (46).

Considering the hemodynamic studies reviewed here, the specific details of each study are worth emphasizing. MRA and
CTA represent valuable options for detecting and confirming large vessel occlusion, but cannot identify the timing of recanalization $(8,11,15,16,37,47-49)$. Furthermore, early imaging changes are the strong predictors of sICH (50) and could be used in association with cerebral circulation parameters. The primary 
limitations of MRA and CTA studies were the time delay in assessment after thrombolytic treatment, the use of intravenous contrast media, and the difficulties in determining the timing of recanalization $(6,9,12,48,49)$. However, it is well established that the presence and timing of brain arterial recanalization correlates with clinical outcome, hemorrhagic complications, and infarct size $(14,19-22,25,29,31,36,37)$. For this purpose, TCD ultrasonography remains a valuable choice, as this method exhibits the following advantages: (1) device portability, (2) low cost of the method, and (3) real-time monitoring during thrombolysis $(3,18,20-23,25,26,30,34,36,37)$. TCD ultrasound may also play a therapeutic role during thrombolysis; a recent systematic review revealing that sonothrombolysis associated with rtPA is a safe procedure that increases recanalization rate in the acute ischemic stroke setting $(51,52)$. However, TCD is operator-dependent, cannot reliably monitor small brain artery occlusion, and does not determine the exact site of occlusion. Therefore, in the future, a combination of methods may be important.

Only variables that, in the retrieved papers, presented significant correlation with outcome (clinical or sICH) in a multivariate analysis were included in the present review. The main variables associated with clinical outcome or sICH were recanalization, reocclusion, and the presence and site of occlusion. Our metaanalysis showed that recanalization is significantly associated with functional and neurological outcomes, but not with sICH. In fact, some studies have shown that the time of recanalization is associated with neurological recovery (21), and the persistence of occlusion is associated to $\mathrm{sICH}$ (36). Our findings are in agreement with a previous meta-analysis, which found significant association between recanalization and clinical outcome (OR: 4.43) and no association between recanalization and $\mathrm{sICH}$, but comparisons should be made with caution because the previous meta-analysis evaluated intravenous, intra-arterial, and mechanical therapies (53).

Most of the conclusions presented in this paper have already been presented in endovascular therapy (EVT) trials. However, some issues, such as reocclusion, are more suitable for investigation by non-invasive imaging techniques. Furthermore, we believe that the information gathered in this paper, reaffirming the conclusions obtained with EVT trials and pointing the positive and negative aspects of other imaging techniques, is important to support the utilization of multimodality imaging in stroke care. A multimodality approach may provide a better understanding of the natural evolution of this pathology, and perhaps better future selection of patients for interventional therapies, who are currently excluded. Finally, strengthening the importance of different imaging modalities in the intravenous therapy setting is important for centers that still do not have access to interventional therapy, especially in low-income countries.

There are few studies concerning CA during acute and subacute ischemic stroke. Existing publications on CA in ischemic stroke reveal a transient impairment of CA during the subacute stages of major ischemic stroke (54-57). Interestingly, using animal models, it has been demonstrated that rtPA displays neurotoxic properties that can disrupt the blood-brain barrier, damage vessels, and possibly impair the CA (58). To our knowledge, only one study of CA after rtPA treatment in humans is available, which concluded that this treatment does not contribute to impaired CA. However, this study evaluated CA 10-20 h after rtPA treatment; not eliminating the possibility of an initial detrimental effect by rtPA on CA (59).

The limitations of the current review are (1) the search strategy was restricted to just one database, although PubMed comprises a majority of the relevant articles on this topic; (2) the inclusion criteria were limited to research of standard dose of rtPA $(0.9 \mathrm{mg} / \mathrm{kg})$ for thrombolysis, although low dose of rtPA $(0.6 \mathrm{mg} /$ $\mathrm{kg}$ ), other thrombolytic drugs (desmoteplase or tenecteplase), or other methods (mechanical thrombectomy, intra-arterial rtPA) have been investigated; (3) lack of analysis concerning the effect of recanalization time on clinical outcome, although the present meta-analysis showed the clinical impact of recanalization at the first $24 \mathrm{~h}$; (4) use of different imaging modalities for detecting arterial occlusion and recanalization; (5) data heterogeneity (especially number of patients included in each study, quality of study, and average stroke severity) from different publications; and (6) potential publication bias of some outcomes' measures confirmed by the funnel plot and Egger's test.

\section{CONCLUSION}

In conclusion, the use of brain assessments of cerebral circulation before, during, and after rtPA thrombolysis is promising, especially, to predict outcome. Arterial recanalization, presence and site of occlusion, and reocclusion relate to clinical outcome. Future studies of prognostic accuracy should investigate these factors, ideally using more than one method of cerebral hemodynamic assessment. In addition, the evaluation of cerebral blood flow regulation mechanisms during and after rtPA treatment should be explored.

\section{AUTHOR CONTRIBUTIONS}

RN contributed to the conception and design of research; acquisition, analysis, and interpretation of data; statistical analysis; drafting of the manuscript; and approved the final version. EB-S-S and NS contributed to the conception and design; interpretation of data; drafting of the manuscript; and approved the final version. MT, RP, and TR contributed to the analysis and interpretation of data; critical revision of the manuscript for important intellectual content; and approved the final version of the manuscript.

\section{FUNDING}

RN received a grant from São Paulo Research Foundation (FAPESP; grant number: 2013/25953-0).

\section{SUPPLEMENTARY MATERIAL}

The Supplementary Material for this article can be found online at http://journal.frontiersin.org/article/10.3389/fneur.2016.00077 


\section{REFERENCES}

1. Mishra NK, Albers GW, Davis SM, Donnan GA, Furlan AJ, Hacke W, et al. Mismatch-based delayed thrombolysis: a meta-analysis. Stroke (2010) 41(1):e25-33. doi:10.1161/STROKEAHA.109.566869

2. Balami JS, Hadley G, Sutherland BA, Karbalai H, Buchan AM. The exact science of stroke thrombolysis and the quiet art of patient selection. Brain (2013) 136(Pt 12):3528-53. doi:10.1093/brain/awt201

3. Molina CA, Alexandrov AV, Demchuk AM, Saqqur M, Uchino K, AlvarezSabin J, et al. Improving the predictive accuracy of recanalization on stroke outcome in patients treated with tissue plasminogen activator. Stroke (2004) 35(1):151-6. doi:10.1161/01.STR.0000106485.04500.4A

4. Ploneda Perilla AS, Schneck MJ. Unanswered questions in thrombolytic therapy for acute ischemic stroke. Neurol Clin (2013) 31(3):677-704. doi:10.1016/j. ncl.2013.03.006

5. Sillanpaa N, Saarinen JT, Rusanen H, Hakomaki J, Lahteela A, Numminen $\mathrm{H}$, et al. The clot burden score, the Boston Acute Stroke Imaging Scale, the cerebral blood volume ASPECTS, and two novel imaging parameters in the prediction of clinical outcome of ischemic stroke patients receiving intravenous thrombolytic therapy. Neuroradiology (2012) 54(7):663-72. doi:10.1007/ s00234-011-0954-z

6. Albers GW, Thijs VN, Wechsler L, Kemp S, Schlaug G, Skalabrin E, et al. Magnetic resonance imaging profiles predict clinical response to early reperfusion: the diffusion and perfusion imaging evaluation for understanding stroke evolution (DEFUSE) study. Ann Neurol (2006) 60(5):508-17. doi:10.1002/ ana.20976

7. Alsop DC, Makovetskaya E, Kumar S, Selim M, Schlaug G. Markedly reduced apparent blood volume on bolus contrast magnetic resonance imaging as a predictor of hemorrhage after thrombolytic therapy for acute ischemic stroke. Stroke (2005) 36(4):746-50. doi:10.1161/01. STR.0000158913.91058.93

8. Olivot JM, Mlynash M, Thijs VN, Kemp S, Lansberg MG, Wechsler L, et al. Relationships between infarct growth, clinical outcome, and early recanalization in diffusion and perfusion imaging for understanding stroke evolution (DEFUSE). Stroke (2008) 39(8):2257-63. doi:10.1161/ STROKEAHA.107.511535

9. Olivot JM, Mlynash M, Thijs VN, Purushotham A, Kemp S, Lansberg MG, et al. Geography, structure, and evolution of diffusion and perfusion lesions in Diffusion and perfusion imaging Evaluation For Understanding Stroke Evolution (DEFUSE). Stroke (2009) 40(10):3245-51. doi:10.1161/ STROKEAHA.109.558635

10. Rother J, Schellinger PD, Gass A, Siebler M, Villringer A, Fiebach JB, et al. Effect of intravenous thrombolysis on MRI parameters and functional outcome in acute stroke <6 hours. Stroke (2002) 33(10):2438-45. doi:10.1161/01. STR.0000030109.12281.23

11. Derex L, Nighoghossian N, Hermier M, Adeleine P, Berthezene Y, Philippeau $\mathrm{F}$, et al. Influence of pretreatment MRI parameters on clinical outcome, recanalization and infarct size in 49 stroke patients treated by intravenous tissue plasminogen activator. J Neurol Sci (2004) 225(1-2):3-9. doi:10.1016/j. jns.2004.05.020

12. Nighoghossian N, Hermier M, Adeleine P, Derex L, Dugor JF, Philippeau F, et al. Baseline magnetic resonance imaging parameters and stroke outcome in patients treated by intravenous tissue plasminogen activator. Stroke (2003) 34(2):458-63. doi:10.1161/01.STR.0000053850.64877.AF

13. Linfante I, Llinas RH, Selim M, Chaves C, Kumar S, Parker RA, et al. Clinical and vascular outcome in internal carotid artery versus middle cerebral artery occlusions after intravenous tissue plasminogen activator. Stroke (2002) 33(8):2066-71. doi:10.1161/01.STR.0000021001.18101.A5

14. Kimura K, Iguchi Y, Shibazaki K, Aoki J, Uemura J. Early recanalization rate of major occluded brain arteries after intravenous tissue plasminogen activator therapy using serial magnetic resonance angiography studies. Eur Neurol (2009) 62(5):287-92. doi:10.1159/000235753

15. Pialat JB, Wiart M, Nighoghossian N, Adeleine P, Derex L, Hermier M, et al. Evolution of lesion volume in acute stroke treated by intravenous t-PA. J Magn Reson Imaging (2005) 22(1):23-8. doi:10.1002/jmri.20363

16. Baizabal-Carvallo JF, Rosso C, Alonso-Juarez M, Pires C, Samson Y. The hemodynamic status within $24 \mathrm{~h}$ after intravenous thrombolysis predicts infarct growth in acute ischemic stroke. J Neurol (2012) 259(6):1045-50. doi:10.1007/s00415-011-6295-3
17. Sims JR, Rordorf G, Smith EE, Koroshetz WJ, Lev MH, Buonanno F, et al. Arterial occlusion revealed by CT angiography predicts NIH stroke score and acute outcomes after IV tPA treatment. AJNR Am J Neuroradiol (2005) 26(2):246-51.

18. Alexandrov AV, Burgin WS, Demchuk AM, El-Mitwalli A, Grotta JC. Speed of intracranial clot lysis with intravenous tissue plasminogen activator therapy: sonographic classification and short-term improvement. Circulation (2001) 103(24):2897-902. doi:10.1161/01.CIR.103.24.2897

19. Molina CA, Montaner J, Abilleira S, Arenillas JF, Ribo M, Huertas R, et al. Time course of tissue plasminogen activator-induced recanalization in acute cardioembolic stroke: a case-control study. Stroke (2001) 32(12):2821-7. doi:10.1161/hs1201.99821

20. Ribo M, Alvarez-Sabin J, Montaner J, Romero F, Delgado P, Rubiera M, et al. Temporal profile of recanalization after intravenous tissue plasminogen activator: selecting patients for rescue reperfusion techniques. Stroke (2006) 37(4):1000-4. doi:10.1161/01.STR.0000206443.96112.d9

21. Alexandrov AV, Demchuk AM, Felberg RA, Christou I, Barber PA, Burgin WS, et al. High rate of complete recanalization and dramatic clinical recovery during $\mathrm{PA}$ infusion when continuously monitored with $2-\mathrm{MHz}$ transcranial Doppler monitoring. Stroke (2000) 31(3):610-4. doi:10.1161/01.STR.31.3.610

22. Christou I, Alexandrov AV, Burgin WS, Wojner AW, Felberg RA, Malkoff $\mathrm{M}$, et al. Timing of recanalization after tissue plasminogen activator therapy determined by transcranial Doppler correlates with clinical recovery from ischemic stroke. Stroke (2000) 31(8):1812-6. doi:10.1161/01.STR.31.8.1812

23. Rubiera M, Alvarez-Sabin J, Ribo M, Montaner J, Santamarina E, Arenillas JF, et al. Predictors of early arterial reocclusion after tissue plasminogen activator-induced recanalization in acute ischemic stroke. Stroke (2005) 36(7):1452-6. doi:10.1161/01.STR.0000170711.43405.81

24. El-Mitwalli A, Saad M, Christou I, Malkoff M, Alexandrov AV. Clinical and sonographic patterns of tandem internal carotid artery/middle cerebral artery occlusion in tissue plasminogen activator-treated patients. Stroke (2002) 33(1):99-102. doi:10.1161/hs0102.101892

25. Kim YS, Garami Z, Mikulik R, Molina CA, Alexandrov AV, Collaborators C. Early recanalization rates and clinical outcomes in patients with tandem internal carotid artery/middle cerebral artery occlusion and isolated middle cerebral artery occlusion. Stroke (2005) 36(4):869-71. doi:10.1161/01. STR.0000160007.57787.4c

26. Molina CA, Montaner J, Arenillas JF, Ribo M, Rubiera M, Alvarez-Sabin J. Differential pattern of tissue plasminogen activator-induced proximal middle cerebral artery recanalization among stroke subtypes. Stroke (2004) 35(2):486-90. doi:10.1161/01.STR.0000110219.67054.BF

27. Burgin WS, Malkoff M, Felberg RA, Demchuk AM, Christou I, Grotta JC, et al. Transcranial Doppler ultrasound criteria for recanalization after thrombolysis for middle cerebral artery stroke. Stroke (2000) 31(5):1128-32. doi:10.1161/01. STR.31.5.1128

28. Felberg RA, Okon NJ, El-Mitwalli A, Burgin WS, Grotta JC, Alexandrov AV. Early dramatic recovery during intravenous tissue plasminogen activator infusion: clinical pattern and outcome in acute middle cerebral artery stroke. Stroke (2002) 33(5):1301-7. doi:10.1161/01.STR.0000015556.48283.74

29. Molina CA, Alvarez-Sabin J, Montaner J, Abilleira S, Arenillas JF, Coscojuela $\mathrm{P}$, et al. Thrombolysis-related hemorrhagic infarction: a marker of early reperfusion, reduced infarct size, and improved outcome in patients with proximal middle cerebral artery occlusion. Stroke (2002) 33(6):1551-6. doi:10.1161/01. STR.0000016323.13456.E5

30. Alexandrov AV, Grotta JC. Arterial reocclusion in stroke patients treated with intravenous tissue plasminogen activator. Neurology (2002) 59(6):862-7. doi:10.1212/WNL.59.6.862

31. Christou I, Felberg RA, Demchuk AM, Burgin WS, Malkoff M, Grotta JC, et al. Intravenous tissue plasminogen activator and flow improvement in acute ischemic stroke patients with internal carotid artery occlusion. J Neuroimaging (2002) 12(2):119-23. doi:10.1111/j.1552-6569.2002.tb00107.x

32. Thomassen L, Waje-Andreassen U, Naess H, Aarseth J, Russell D. Doppler ultrasound and clinical findings in patients with acute ischemic stroke treated with intravenous thrombolysis. Eur J Neurol (2005) 12(6):462-5. doi:10.1111/j.1468-1331.2005.01008.x

33. Rubiera M, Ribo M, Delgado-Mederos R, Santamarina E, Delgado P, Montaner J, et al. Tandem internal carotid artery/middle cerebral artery occlusion: an independent predictor of poor outcome after systemic thrombolysis. Stroke (2006) 37(9):2301-5. doi:10.1161/01.STR.0000237070.80133.1d 
34. Tsivgoulis G, Saqqur M, Sharma VK, Lao AY, Hill MD, Alexandrov AV, et al. Association of pretreatment blood pressure with tissue plasminogen activator-induced arterial recanalization in acute ischemic stroke. Stroke (2007) 38(3):961-6. doi:10.1161/01.STR.0000257314.74853.2b

35. Delgado-Mederos R, Ribo M, Rovira A, Rubiera M, Munuera J, Santamarina E, et al. Prognostic significance of blood pressure variability after thrombolysis in acute stroke. Neurology (2008) 71(8):552-8. doi:10.1212/01. wnl.0000318294.36223.69

36. Saqqur M, Tsivgoulis G, Molina CA, Demchuk AM, Siddiqui M, Alvarez-Sabin J, et al. Symptomatic intracerebral hemorrhage and recanalization after IV rt-PA: a multicenter study. Neurology (2008) 71(17):1304-12. doi:10.1212/01. wnl.0000313936.15842.0d

37. Delgado-Mederos R, Rovira A, Alvarez-Sabin J, Ribo M, Munuera J, Rubiera $\mathrm{M}$, et al. Speed of tPA-induced clot lysis predicts DWI lesion evolution in acute stroke. Stroke (2007) 38(3):955-60. doi:10.1161/01.STR.0000257977.32525.6e

38. Uzuner N, Ozdemir O, Tekgol Uzuner G. Relationship between pulsatility index and clinical course of acute ischemic stroke after thrombolytic treatment. Biomed Res Int (2013) 2013:265171. doi:10.1155/2013/265171

39. Labiche LA, Malkoff M, Alexandrov AV. Residual flow signals predict complete recanalization in stroke patients treated with TPA. J Neuroimaging (2003) 13(1):28-33. doi:10.1111/j.1552-6569.2003.tb00153.x

40. Saqqur M, Tsivgoulis G, Molina CA, Demchuk AM, Shuaib A, Alexandrov $\mathrm{AV}$, et al. Residual flow at the site of intracranial occlusion on transcranial Doppler predicts response to intravenous thrombolysis: a multi-center study. Cerebrovasc Dis (2009) 27(1):5-12. doi:10.1159/000172628

41. Saqqur M, Uchino K, Demchuk AM, Molina CA, Garami Z, Calleja S, et al. Site of arterial occlusion identified by transcranial Doppler predicts the response to intravenous thrombolysis for stroke. Stroke (2007) 38(3):948-54. doi:10.1161/01.STR.0000257304.21967.ba

42. Saqqur M, Molina CA, Salam A, Siddiqui M, Ribo M, Uchino K, et al. Clinical deterioration after intravenous recombinant tissue plasminogen activator treatment: a multicenter transcranial Doppler study. Stroke (2007) 38(1):69-74. doi:10.1161/01.STR.0000251800.01964.f6

43. Schellinger PD, Fiebach JB, Hacke W. Imaging-based decision making in thrombolytic therapy for ischemic stroke: present status. Stroke (2003) 34(2):575-83. doi:10.1161/01.STR.0000051504.10095.9C

44. Huang Y, Sharma VK, Robinson T, Lindley RI, Chen X, Kim JS, et al. Rationale, design, and progress of the ENhanced Control of Hypertension ANd Thrombolysis strokE stuDy (ENCHANTED) trial: an international multicenter $2 \times 2$ quasi-factorial randomized controlled trial of low- vs. standard-dose rt-PA and early intensive vs. guideline-recommended blood pressure lowering in patients with acute ischaemic stroke eligible for thrombolysis treatment. Int J Stroke (2015) 10(5):778-88. doi:10.1111/ijs. 12486

45. Powers WJ, Derdeyn CP, Biller J, Coffey CS, Hoh BL, Jauch EC, et al. 2015 American Heart Association/American Stroke Association focused update of the 2013 guidelines for the early management of patients with acute ischemic stroke regarding endovascular treatment: a guideline for healthcare professionals from the American Heart Association/American Stroke Association. Stroke (2015) 46(10):3020-35. doi:10.1161/STR.0000000000000074

46. Liberati A, Altman DG, Tetzlaff J, Mulrow C, Gotzsche PC, Ioannidis JP, et al. The PRISMA statement for reporting systematic reviews and meta-analyses of studies that evaluate healthcare interventions: explanation and elaboration. BMJ (2009) 339:b2700. doi:10.1136/bmj.b2700

47. Sillanpaa N, Saarinen JT, Rusanen H, Hakomaki J, Lahteela A, Numminen $\mathrm{H}$, et al. CT perfusion ASPECTS in the evaluation of acute ischemic stroke: thrombolytic therapy perspective. Cerebrovasc Dis Extra (2011) 1(1):6-16. doi:10.1159/000324324
48. Aviv RI, Mandelcorn J, Chakraborty S, Gladstone D, Malham S, Tomlinson G, et al. Alberta Stroke Program Early CT Scoring of CT perfusion in early stroke visualization and assessment. AJNR Am J Neuroradiol (2007) 28(10):1975-80. doi:10.3174/ajnr.A0689

49. Butcher K, Parsons M, Baird T, Barber A, Donnan G, Desmond P, et al. Perfusion thresholds in acute stroke thrombolysis. Stroke (2003) 34(9):215964. doi:10.1161/01.STR.0000086529.83878.A2

50. Barber PA, Demchuk AM, Zhang J, Buchan AM. Validity and reliability of a quantitative computed tomography score in predicting outcome of hyperacute stroke before thrombolytic therapy. ASPECTS Study Group. Alberta Stroke Programme Early CT Score. Lancet (2000) 355(9216):1670-4. doi:10.1016/ S0140-6736(00)02237-6

51. Bor-Seng-Shu E, Nogueira Rde C, Figueiredo EG, Evaristo EF, Conforto $A B$, Teixeira MJ. Sonothrombolysis for acute ischemic stroke: a systematic review of randomized controlled trials. Neurosurg Focus (2012) 32(1):E5. doi:10.3171/2011.10.FOCUS11251

52. Alexandrov AV, Demchuk AM, Burgin WS, Robinson DJ, Grotta JC, Investigators C. Ultrasound-enhanced thrombolysis for acute ischemic stroke: phase I. Findings of the CLOTBUST trial. J Neuroimaging (2004) 14(2):113-7. doi:10.1111/j.1552-6569.2004.tb00226.x

53. Rha JH, Saver JL. The impact of recanalization on ischemic stroke outcome: a meta-analysis. Stroke (2007) 38(3):967-73. doi:10.1161/01. STR.0000258112.14918.24

54. Reinhard M, Rutsch S, Lambeck J, Wihler C, Czosnyka M, Weiller C, et al. Dynamic cerebral autoregulation associates with infarct size and outcome after ischemic stroke. Acta Neurol Scand (2012) 125(3):156-62. doi:10.1111/j.1600-0404.2011.01515.x

55. Salinet AS, Robinson TG, Panerai RB. Cerebral blood flow response to neural activation after acute ischemic stroke: a failure of myogenic regulation? J Neurol (2013) 260(10):2588-95. doi:10.1007/ s00415-013-7022-z

56. Dawson SL, Panerai RB, Potter JF. Serial changes in static and dynamic cerebral autoregulation after acute ischaemic stroke. Cerebrovasc Dis (2003) 16(1):69-75. doi:10.1159/000070118

57. Reinhard M, Roth M, Guschlbauer B, Harloff A, Timmer J, Czosnyka M, et al. Dynamic cerebral autoregulation in acute ischemic stroke assessed from spontaneous blood pressure fluctuations. Stroke (2005) 36(8):1684-9. doi:10.1161/01.STR.0000173183.36331.ee

58. Ishrat T, Soliman S, Guan W, Saler M, Fagan SC. Vascular protection to increase the safety of tissue plasminogen activator for stroke. Curr Pharm Des (2012) 18(25):3677-84. doi:10.2174/138161212802002779

59. Reinhard M, Wihler C, Roth M, Harloff A, Niesen WD, Timmer J, et al. Cerebral autoregulation dynamics in acute ischemic stroke after rtPA thrombolysis. Cerebrovasc Dis (2008) 26(2):147-55. doi: $10.1159 / 000139662$

Conflict of Interest Statement: The authors declare that the research was conducted in the absence of any commercial or financial relationships that could be construed as a potential conflict of interest.

Copyright $\odot 2016$ Nogueira, Bor-Seng-Shu, Saeed, Teixeira, Panerai and Robinson. This is an open-access article distributed under the terms of the Creative Commons Attribution License (CC BY). The use, distribution or reproduction in other forums is permitted, provided the original author(s) or licensor are credited and that the original publication in this journal is cited, in accordance with accepted academic practice. No use, distribution or reproduction is permitted which does not comply with these terms. 